\title{
ANALISIS KEANDALAN PENYULANG PAJAJARAN 20KV MENGGUNAKAN METODE SECTION TECHNIQUE UNTUK ASIAN GAMES XVIII DI PALEMBANG
}

\author{
Dian Eka Putra ${ }^{1}$, M. Nurhadiyanto ${ }^{2}$ \\ ${ }^{1,2}$ Program Studi Teknik Elektro Fakultas Teknik Universitas Palembang \\ e-mail : dianekaputra90@gmail.com ${ }^{1}$, a.nurhadiyanto123@gmail.com ${ }^{2}$
}

\begin{abstract}
Abstrak-- Penyulang Pajajaran $20 \mathrm{kV}$ sebagai salah satu penyulang yang menyupai energi listrik ke Jakabaring Sport City (JSC). Keandalan distribusi tegangan $20 \mathrm{kV}$ mempenggaruhi perhelatan ASEAN GAMES ke XVIII di Jakabaring Sport City (JSC). Permasalahan yang mendasar pada distribusi daya listrik adalah pada mutu, kontinuitas dan ketersediaan pelayanan daya listrik pada pelanggan. Keandalan menggambarkan suatu ukuran tingkat pelayanan penyediaan tenaga listrik dari sistem sangat dipengaruhi oleh konfigurasi sistem, alat pengaman yang terpasang dan sistem proteksinya. Untuk mengetahui keandalan Pajajaran $20 \mathrm{kV}$ maka ditetapkan suatu indeks keandalan yaitu besaran untuk membandingkan penampilan suatu sistem distribusi. Indeks keandalan dengan Metode Section Technique untuk mengetahui indikator yang dinyatakan dalam besaran probabilitas. Indeks Keandalan titik beban yang biasanya digunakan meliputi laju pemutusan beban rata-rata, waktu keluar rata-rata dan lama pemutusan beban rata-rata Indeks keandalan sistem yang banyak digunakan antara lain Metode Section Technique pada Sistem Average Interruption duration Index (SAIDI) diperoleh nilai 2,5707 jam/pel dan Metode Section Technique Sistem Average Interruption Frequensy Index (SAIFI) diperoleh nilai $2,6933 \mathrm{kali} /$ pel.
\end{abstract}

Kata Kunci : Asian Games ke XVIII, Jakabaring Sport City (JSC), Penyulang 20 kV, SAIDI, SAIFI.

\begin{abstract}
Abstrack - $20 \mathrm{kv}$ Pajajaran feeder as one of the suppliers that resembles electrical energy to Jakabaring Sport City (JSC). The reliability of the $20 \mathrm{kV}$ voltage distribution affects the XVIII ASEAN GAMES event at Jakabaring Sport City (JSC). The fundamental problems in the distribution of electric power are the quality, continuity and availability of electrical power services to customers. Reliability illustrates a measure of the level of service of electricity supply from a system greatly influenced by system configuration, safety devices installed and protection systems. To determine the reliability of Pajajaran $20 \mathrm{kV}$, a reliability index is determined, namely the magnitude to compare the appearance of a distribution system. Reliability index with Section Technique Method to find out indicators that are expressed in probability quantities. Reliability index load points that are usually used include the average load termination rate, average time out and load termination average system reliability index that is widely used, among others, Section Technique Method on the Average Interruption duration Index (SAIDI) system obtained value 2, 5707 hours / mop and the Average Interruption Frequency Index (SAIFI) Section Technique Method obtained a value of 2.6933 times / mop
\end{abstract}

Keywords : XVIII Asian Games, Jakabaring Sport City (JSC), 20 kV feeders, SAIDI, SAIFI

\section{PENDAHULUAN}

Adanya event berskala international pada tahun 2018, tepatnya Agustus sampai dengan September 2018, di Jakarta dan Palembang maka sebagai salah satu kota yang didaulat sebagai penyelenggara even empat tahunan berskala internasional Asian Games XVIII, Palembang dituntut dapat memberikan kemudahan dan kenyamanan bagi sekitar 45 negara kontestan pada turnament Asian Games.salah satu bentuk kenyamanan yaitu adanya keandalan pada penyulang $20 \mathrm{kV}$ sebagai penyuplai energi listrik dalam kegiatan penyelenggaraan ASEAN Games di Kota Palembang, Dengan 
Metode Section Technique adalah suatu metode analisis evaluasi sistem Keandalan jaringan distribusi tenaga listrik. Jaringan distribusi yang di analisa adalah Keandalan Penyulang Pajajaran pada Gardu Induk New Jakabaring Area kerja PLN Rayon Ampera, sebagai salah satu Penyulang yang menyuplai pasokan listrik pada kompleks Jakabaring Sport City. Masalah utaman dalam operasional sistem distribusi adalah bagaimana mengatasi gangguan dengan cepat karena gangguan terbanyak dalam sistem tenaga listrik terdapat dalam sistem distribusi Jaringan Distribusi tegangan menengah atau juga disebut Jaringan distribusi primer [4]. Dalam memenuhi suplai tenaga listrik diperlukan beberapa insfrastruktur peralatan jaringan transmisi tegangan tinggi agar dapat mengalirkan energi listrik ke konsumen [9]. Untuk memenuhi keandalan penyediaan energi listrik diperlukan nilai ratio keandalan suplai tenaga listrik dari penyulang tengangan menengah berupa nilai SAIDI dan SAIFI.

\section{TINJAUAN PUSTAKA}

\section{Jaringan Distribusi Primer dan Sekunder}

Jaringan tenaga listrik distribusi primer dan sekunder selalu harus ada dan berhubungan langsung dengan pelayanan energi listrik konsumen. Disamping itu, selain harus ada tetapi juga harus dipikirkan mengenai masalah bentuk atau konfigurasi dari sistem penyalurannya, mutu dan keandalanya, dan tentu saja menjangkau untuk seluruh tingkatan konsumen [2]

\section{Tegangan dan Keandalan}

Keandalan distribusi merupakan topik yang telah mendapat perhatian secara luas dari seluruh masyarakat termasuk para teknisi, engineer, pelanggan dan lain-lain. Hal ini disebabkan karena kinerja keandalan distribusi secara langsung mempengaruhi pelanggan (konsumen).Keandalan distribusi menurut difinisi kamus IEEE adalah kemampuan sistem distribusi untuk melakukan fungsinya pada kondisi normal untuk periode waktu tersebut tanpa kegagalan (failure) [3]. Sistem distribusi sangat dipengaruh oleh cuaca. Dalam beberapa iklim, salju dan es merupakan masalah besar dan pada daerah lain, petir merupakan penyebab pemutus utama dalam pelayanan listrik. cuaca menyebabkan banyak gangguan pada sistem distribusi[3]. Untuk melihat unjuk kerja (performance) dari pengusahaan ketenagalistrikan yang diusahakan PT PLN digunakan SAIDI dan SAIFI. Terdapat standar tingkat jaminan pada sistem distribusi yang didasarkan menurut konfigurasi jaringan dengan menjadikan nilai $\mathrm{F}$ dan D di PLN Distribusi DKI dan 
Tangerang pada tabel 2.1 sebagai dasar untuk menentukan tingkat jaminan. Bagi daerah dikalikan dengan faktor penyesuaian $\mathrm{F}$ dan $\mathrm{D}$ terlihat pada tabel 1. [7]

Tabel 1. Nilai F dan D di PLN DKI dan Tangerang

\begin{tabular}{l|c|c}
\hline \multicolumn{1}{c|}{ Jenis system } & F (kali/tahun) & D (jam/tahun) \\
\hline SUTM Radial & 27 & 177 \\
SUTM dengan PBO & 11 & 58 \\
SKTM spindel tanpa PPJD & 1,7 & 6,25 \\
SKTM Spindel dengan PPJD & 1,7 & 4,77 \\
SKTM sistem Gugus & 1,7 & 5 \\
\hline
\end{tabular}

Tabel 2. Nilai F dan D

\begin{tabular}{l|c}
\hline \multicolumn{1}{c|}{ Jenis sistem } & F (kali/tahun) \\
\hline Jawa dan Bali & 1,1 \\
Sumatera & 1,2 \\
Kalimantan dan Sulawesi & 1,3 \\
Maluku, NTB dan NTT & 1,4 \\
Papua & 1,5 \\
\hline
\end{tabular}

\section{Metode Section Technique}

Metode section Tecchnique merupakan suatu metode terstruktur untuk mengevaluasi sistem keandalan sistem distribusi tenaga listrik berdasarkan pada bagaimana suatu kegagalan dari suatu peralatan mempengaruhi operasi sistem. Efek atau konsekuensi dari gangguan secara sistematis di indentifikasi dengan penganalisaan apa yang terjadi jka gangguan terjadi kemudian masing-masing kegagalan peralatan dianalisa dari semua titik beban (load point).

Pendekatan yang dilakukan dari bawah keatas dimana yang dipertimbangkan satu mode kegagalan pada satu waktu. Indeks keandalan yang dihitung adalah indeks-indeks titik beban dan indeksindeks sistem baik secara section maupun keseluruhan, indeks titik beban antara lain :

a) Frekuensi gangguan (failurate rate) untuk setiap titik beban, merupakan penjumlahan laju kegagalan semua peralatan yang berpengaruh terhadap titik beban, dengan persamaan:

$$
\lambda_{T B}=\sum_{i=k} \lambda_{i}
$$

Dimana:

$\lambda_{i}$ : laju kegagalan untuk peralatan sejumlah $\mathrm{k}$

$\mathrm{k}$ :semua peralatan yang berpengaruh terhadap titik beban

b) Lama/durasi gangguan tahunan rata-rata untuk titik beban UTB, dengan persamaan :

$$
\mathrm{U}_{L P}=\sum_{i=k} \mathrm{U}_{i}=\sum_{i=k} \lambda_{i} x \mathrm{r}_{j}
$$

Dimana:

rj :waktuperbaikan (repair time atauswitching time)

Berdasarkan indeks-indeks titik beban ini, diperoleh sejumlah indeks keandalan untuk mengetahui indeks keandalan system secara keseluruhan yang dapat dievaluasi dan bias didapatkan dengan lengkap mengenai kinerja sistem. Indeks-indeks ini adalah frekuensi dan lama pemadaman rata-rata tahunan. 


\section{Indeks Kegagalan Peralatan Sistem Distribusi}

Berikut ini adalah tabel data kegagalan untuk saluran udara dan peralatan distribusi yang melingkupi frekuensi kegagalan, waktu pemadaman dan waktu pemindahan berdasarkang Keandalan sistem Distribusi $20 \mathrm{kV}$ dan 6 kV,( SPLN No. 59: 1985 ) yang ditunjukkan masingmasing pada Tabel 3 .

Tabel 3 Standar Laju Kegagalan dan Waktu Pemulihan

\begin{tabular}{c|l|l|c}
\hline No & \multicolumn{1}{|c|}{ Komponen } & Laju Kegagalan $(\lambda)$ & $\begin{array}{c}\text { Waktu } \\
\text { Pemulihan }\end{array}$ \\
\hline 1 & Saluran Udara & $0,2 /$ Km/tahun & 4 \\
\hline 2 & Pemutus Tenaga & $0,004 /$ Unit/tahun & 10 \\
\hline 3 & Sakelar Pemisah & $0,003 /$ Unit/tahun & 10 \\
\hline 4 & Sakelar Beban (Sectionalizer) & $0,003 /$ Unit/tahun & 10 \\
\hline 5 & Trafo Distribusi & $0,005 /$ Unit/tahun & 10 \\
\hline
\end{tabular}

\section{SAIFI (System Average Interruption Frequency Index)}

Untuk mendapatkan nilai SAIFI pada metode ini dilakukan menggunakan persamaan :

$$
S A I F I=\frac{\sum N T B \times \lambda_{T B}}{N}
$$

NTB : jumlah konsumen pada titikbeban

$\mathrm{N} \quad$ : jumlah konsumen pada sistem

$\lambda_{T B} \quad$ : frekuensi gangguan peralatan pada sistem

\section{SAIDI (System Average Interruption Duration Index)}

Untuk mendapatkan nilai SAIDI pada metode ini dilakukan menggunakan persamaan :

$$
S A I F I=\frac{\sum N_{T B} \mathrm{XU}_{T B}}{N}
$$

NTB : jumlah konsumen pada titik beban

$\mathrm{N} \quad$ : jumlah konsumen pada sistem

$\mathrm{U}_{T B} \quad$ : durasi gangguan peralatan

\section{METODE PENELITIAN}

Untuk menganalisa kehandalan suatu sistem dibutuhkan pengumpulan data yang lengkap dan terperinci di PT.PLN (Persero) Area Palembang Rayon Ampera. Hal ini dimaksudkan agar analisa yang dilakukan tepat sasaran. Adapun data-data yang dibutuhkan untuk melakukan analisa kehandalan suatu sistem distribusi adalah sebagai berikut:

Untuk mengukur suatu keandalan suatu sistem maka diperlukan patokan/standar yang berguna untuk menilai keadaan sistem dalam kondisi baik ataupun kurang baik. Maka 
berdasarkan nilai indeks keandalan telah memenuhi standart ( IEEE P1366-2017), jika memenuhi:

SAIFI : 1,59 kali/pelanggan/tahun

$>\quad$ SAIDI : 4,38jam/pelanggan/tahun

Target SAIDI SAIFI Penyulang Padjajaran di PLN Rayon Ampera adalah sebagai berikut:

$>\quad$ SAIFI : 2,49 kali/pelanggan/tahun

$>$ SAIDI : $3,38 \mathrm{jam} /$ pelanggan/tahun

Pada Metode Section Technique, yang dihitung indeks keandalannya yaitu: SAIFI, SAIDI.

\section{PERHITUNGAN DAN ANALISA}

Penyulang Pajajaran disuplai dari Gardu Induk New Jakabaring dengan daya 60 MVA.Penyulang ini memiliki variasi beban di titik beban berupa beban industri dan rumah tangga. Penyulang Pajajaran memiliki 52 titik beban berupa trafo distribusi dengan total pelanggan 9.914 dan terdiri dari 71 saluran udara. Jumlah sectionalizer Penyulang Pajajaran adalah 3 buah dan penyulang terbagi menjadi 4 section. Pembagian Section sebagaimana gambar dibawah ini:

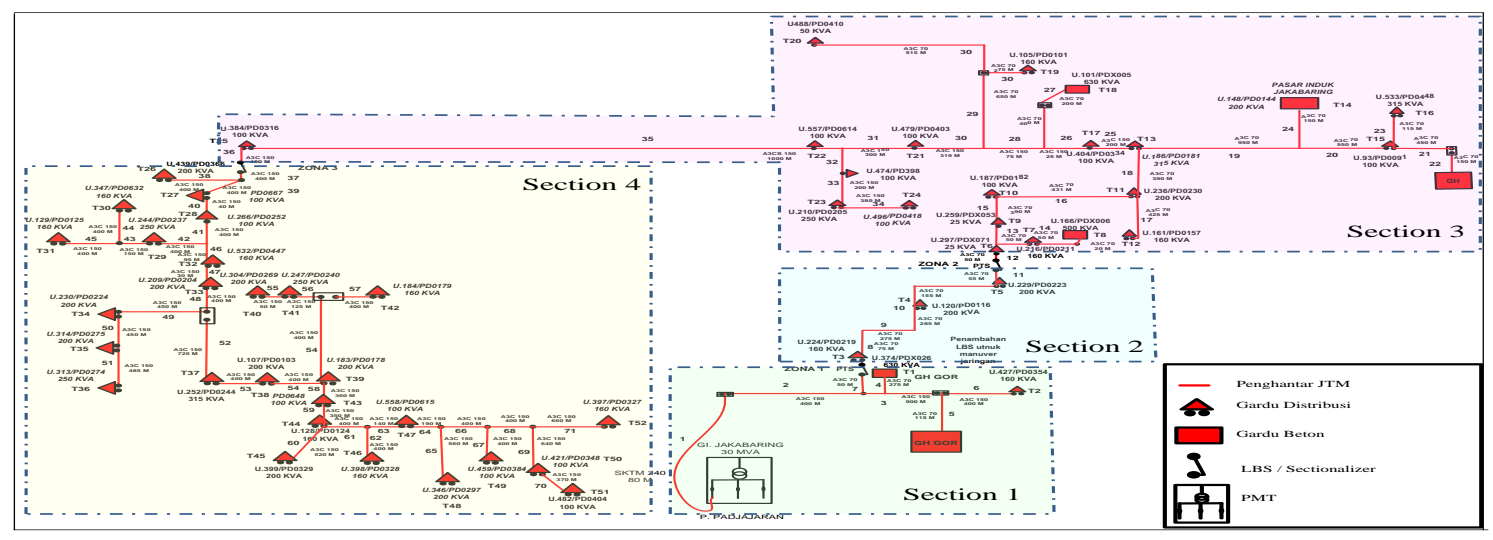

Gambar 1. Pembagian Section Penyulang Pajajaran.

\section{Indeks Keandalan Menggunakan Metode Section Technique}

Dilakukan analisis evaluasi keandalan berdasarkan data yang telah didapat dengan menggunakan data panjang saluran udara dan jumlah pelanggan tiap titik beban. Nilai frekuensi kegagalan $(\lambda)$ untuk setiap titik beban yang didapat dari penjumlahan failurate rate peralatan yang mempengaruhi setiap Titik Beban (TB) dan perkalian failure rate saluran dengan panjang tiap salurannya, adapun perhitungan nilai frekuensi kegagalan $(\lambda)$ seperti persamaan berikut :

$$
\lambda_{T B}=\sum_{i=k} \lambda_{i}
$$

$$
\lambda_{T 1-T 2}=\text { Failure rate } x \text { Volume }
$$


Hasil perhitungan secara lengkap frekuensi kegagalan section 1 - 4 ditunjukkan pada Tabel 4.

Frekuensi kegagalan $(\boldsymbol{\lambda})$ Section I:

Tabel 4.1. Frekuensi Kegagalan Section I

\begin{tabular}{l|l|c|c|c}
\hline No & \multicolumn{1}{|c|}{ Nama Peralatan } & $\begin{array}{c}\text { Fairlure Rate } \\
\text { Peralatan }\end{array}$ & $\begin{array}{c}\text { Volume } \\
\text { (unit) }\end{array}$ & $\begin{array}{c}\boldsymbol{\lambda} \\
\text { ( kegagalan/tahun) }\end{array}$ \\
\hline 1 & Circuit Breaker & 0,004 & 1 & 0,004 \\
\hline 2 & Trafo T1-T2 & 0,005 & 2 & 0,010 \\
\hline 3 & Sectionalizer S1 & 0,003 & 1 & 0,003 \\
\hline \multicolumn{3}{c}{ TOTAL } \\
\hline
\end{tabular}

Tabel 4.2. Frekuensi Kegagalan Section II

\begin{tabular}{c|l|c|c|c}
\hline No & \multicolumn{1}{|c|}{ Nama Peralatan } & $\begin{array}{c}\text { Fairlure Rate } \\
\text { Peralatan }\end{array}$ & $\begin{array}{c}\text { Volume } \\
(\mathbf{k m})\end{array}$ & $\begin{array}{c}\boldsymbol{\lambda} \\
\text { ( kegagalan/tahun) }\end{array}$ \\
\hline 1 & Saluran L1 & 0,2 & 0,080 & 0,016 \\
\hline 2 & Saluran L2 & 0,2 & 0,400 & 0,08 \\
\hline 3 & Saluran L3 & 0,2 & 0,900 & 0,18 \\
\hline 4 & Saluran L4 & 0,2 & 0,275 & 0,055 \\
\hline 5 & Saluran L5 & 0,2 & 0,115 & 0,023 \\
\hline 6 & Saluran L6 & 0,2 & 0,400 & 0,08 \\
\hline 7 & Saluran L7 & 0,2 & 0,050 & 0,01 \\
\hline & \multicolumn{4}{|c|}{} \\
\hline
\end{tabular}

Tabel 4.3. Jumlah Frekuensi Kegagalan Section I

\begin{tabular}{c|c|c}
\hline No & Nama Peralatan & $\begin{array}{c}\boldsymbol{\lambda} \\
\text { ( kegagalan/tahun) }\end{array}$ \\
\hline 1 & Frekuensi Kegagalan Tabel 4.1 Sec I & 0,017 \\
\hline 2 & Frekuensi Kegagalan Tabel 4.2 Sec I & 0,444 \\
\hline \multicolumn{2}{c}{ TOTAL } & $\mathbf{0 , 4 6 1}$ \\
\hline
\end{tabular}

Frekuensi kegagalan $(\lambda)$ Section II:

Tabel 5.1. Frekuensi Kegagalan Section II

\begin{tabular}{c|l|c|c|c}
\hline No & \multicolumn{1}{|c|}{ Nama Peralatan } & $\begin{array}{c}\text { Fairlure Rate } \\
\text { Peralatan }\end{array}$ & $\begin{array}{c}\text { Volume } \\
\text { (unit) }\end{array}$ & $\begin{array}{c}\boldsymbol{\lambda} \\
\text { ( kegagalan/tahun) }\end{array}$ \\
\hline 1 & Circuit Breaker & 0,004 & 0 & 0 \\
\hline 2 & Trafo T1-T2 & 0,005 & 3 & 0,015 \\
\hline 3 & Sectionalizer S1 & 0,003 & 1 & 0,003 \\
\hline \multicolumn{3}{c}{ TOTAL } \\
\hline
\end{tabular}

Tabel 5.2. Frekuensi Kegagalan Section II

\begin{tabular}{c|l|c|c|c}
\hline No & \multicolumn{1}{|c|}{ Nama Peralatan } & $\begin{array}{c}\text { Fairlure Rate } \\
\text { Peralatan }\end{array}$ & $\begin{array}{c}\text { Volume } \\
(\mathbf{k m})\end{array}$ & $\begin{array}{c}\boldsymbol{\lambda} \\
\text { ( kegagalan/tahun) }\end{array}$ \\
\hline 1 & Saluran L8 & 0,2 & 0,075 & 0,015 \\
\hline 2 & Saluran L9 & 0,2 & 0,275 & 0,055 \\
\hline
\end{tabular}




\begin{tabular}{l|l|l|l|l}
3 & Saluran L10 & 0,2 & 0,285 & 0,057 \\
\hline 4 & Saluran L11 & 0,2 & 0,055 & 0,011 \\
\hline \multicolumn{3}{c}{ TOTAL } \\
\hline
\end{tabular}

Tabel 5.3. Jumlah Frekuensi Kegagalan Section II

\begin{tabular}{c|c|c}
\hline No & Nama Peralatan & $\boldsymbol{\lambda}$ ( kegagalan/tahun) \\
\hline 1 & Frekuensi Kegagalan Tabel 5.1 Sec II & 0,018 \\
\hline 2 & Frekuensi Kegagalan Tabel 5.2 Sec II & 0,138 \\
\hline \multicolumn{2}{c}{ TOTAL } & $\mathbf{0 , 1 5 6}$ \\
\hline
\end{tabular}

Frekuensi kegagalan $(\boldsymbol{\lambda})$ Section III :

Tabel 6.1. Frekuensi Kegagalan Section III

\begin{tabular}{c|l|c|c|c}
\hline No & \multicolumn{1}{|c|}{ Nama Peralatan } & $\begin{array}{c}\text { Fairlure Rate } \\
\text { Peralatan }\end{array}$ & $\begin{array}{c}\text { Volume } \\
\text { (unit) }\end{array}$ & $\begin{array}{c}\boldsymbol{\lambda} \\
\text { (kegagalan/tahun) }\end{array}$ \\
\hline 1 & Circuit Breaker & 0,004 & 0 & 0 \\
\hline 2 & Trafo T6-T36 & 0,005 & 31 & 0,155 \\
\hline 3 & Sectionalizer S1 & 0,003 & 1 & 0,003 \\
\hline \multicolumn{3}{c}{ TOTAL } \\
\hline
\end{tabular}

Tabel 6.2. Frekuensi Kegagalan Section III

\begin{tabular}{|c|c|c|c|c|}
\hline No & Nama Peralatan & $\begin{array}{c}\text { Fairlure Rate } \\
\text { Peralatan } \\
\end{array}$ & $\begin{array}{c}\text { Volume } \\
(\mathbf{k m})\end{array}$ & $\begin{array}{c}\lambda \\
\text { ( kegagalan/tahun) }\end{array}$ \\
\hline 1 & Saluran L12 & 0,2 & 0,050 & 0,010 \\
\hline 2 & Saluran L13 & 0,2 & 0,050 & 0,010 \\
\hline 3 & Saluran L14 & 0,2 & 0,050 & 0,010 \\
\hline 4 & Saluran L15 & 0,2 & 0,390 & 0,078 \\
\hline 5 & Saluran L16 & 0,2 & 0,431 & 0,086 \\
\hline 6 & Saluran L17 & 0,2 & 0,425 & 0,085 \\
\hline 7 & Saluran L18 & 0,2 & 0,930 & 0,186 \\
\hline 8 & Saluran L19 & 0,2 & 0,950 & 0,190 \\
\hline 9 & Saluran L20 & 0,2 & 0,550 & 0,110 \\
\hline 10 & Saluran L21 & 0,2 & 0,450 & 0,090 \\
\hline 11 & Saluran L22 & 0,2 & 0,150 & 0,030 \\
\hline 12 & Saluran L23 & 0,2 & 0,115 & 0,023 \\
\hline 13 & Saluran L24 & 0,2 & 0,150 & 0,030 \\
\hline 14 & Saluran L25 & 0,2 & 0,200 & 0,040 \\
\hline 15 & Saluran L26 & 0,2 & 0,025 & 0,005 \\
\hline 16 & Saluran L27 & 0,2 & 0,200 & 0,040 \\
\hline 17 & Saluran L28 & 0,2 & 0,075 & 0,015 \\
\hline 18 & Saluran L29 & 0,2 & 0,650 & 0,130 \\
\hline 19 & Saluran L30 & 0,2 & 0,275 & 0,055 \\
\hline 20 & Saluran L31 & 0,2 & 0,319 & 0,064 \\
\hline 21 & Saluran L32 & 0,2 & 0,300 & 0,060 \\
\hline 22 & Saluran L33 & 0,2 & 0,200 & 0,040 \\
\hline
\end{tabular}




\begin{tabular}{l|l|l|l|l}
23 & Saluran L34 & 0,2 & 0,380 & 0,076 \\
\hline 24 & Saluran L35 & 0,2 & 1,000 & 0,200 \\
\hline 25 & Saluran L36 & 0,2 & 0,040 & 0,008 \\
\hline \multicolumn{3}{r|}{ TOTAL } \\
\hline
\end{tabular}

Tabel 6.3. Jumlah Frekuensi Kegagalan Section III

\begin{tabular}{|c|c|c|}
\hline No & Nama Peralatan & $\begin{array}{c}\lambda \\
\text { ( kegagalan/tahun) }\end{array}$ \\
\hline 1 & Frekuensi Kegagalan Tabel 6.1 Sec III & 0,158 \\
\hline 2 & Frekuensi Kegagalan Tabel 6.2 Sec III & 1,671 \\
\hline \multicolumn{2}{|r|}{ TOTAL } & 1,829 \\
\hline
\end{tabular}

Frekuensi kegagalan $(\boldsymbol{\lambda})$ Section IV :

Tabel 7.1. Frekuensi Kegagalan Section IV

\begin{tabular}{c|l|c|c|c}
\hline No & Nama Peralatan & $\begin{array}{c}\text { Fairlure Rate } \\
\text { Peralatan }\end{array}$ & $\begin{array}{c}\text { Volume } \\
\text { (unit) }\end{array}$ & $\begin{array}{c}\boldsymbol{\lambda} \\
\text { ( kegagalan/tahun) }\end{array}$ \\
\hline 1 & Circuit Breaker & 0,004 & 0 & 0 \\
\hline 2 & Trafo T37-T52 & 0,005 & 16 & 0,080 \\
\hline 3 & Sectionalizer S1 & 0,003 & 1 & 0,003 \\
\hline \multicolumn{3}{c}{ TOTAL } \\
\hline
\end{tabular}

Tabel 7.2. Frekuensi Kegagalan Section IV

\begin{tabular}{|c|c|c|c|c|}
\hline No & Nama Peralatan & $\begin{array}{c}\text { Fairlure Rate } \\
\text { Peralatan }\end{array}$ & $\begin{array}{c}\text { Volume } \\
(\mathbf{k m})\end{array}$ & $\begin{array}{c}\lambda \\
\text { ( kegagalan/tahun) }\end{array}$ \\
\hline 1 & Saluran L37 & 0,2 & 0,060 & 0,012 \\
\hline 2 & Saluran L38 & 0,2 & 0,025 & 0,005 \\
\hline 3 & Saluran L39 & 0,2 & 0,040 & 0,008 \\
\hline 4 & Saluran L40 & 0,2 & 0,060 & 0,012 \\
\hline 5 & Saluran L41 & 0,2 & 0,040 & 0,008 \\
\hline 6 & Saluran L42 & 0,2 & 0,025 & 0,005 \\
\hline 7 & Saluran L43 & 0,2 & 0,035 & 0,007 \\
\hline 8 & Saluran L44 & 0,2 & 0,025 & 0,005 \\
\hline 9 & Saluran L45 & 0,2 & 0,035 & 0,007 \\
\hline 10 & Saluran L46 & 0,2 & 0,030 & 0,006 \\
\hline 11 & Saluran L47 & 0,2 & 0,030 & 0,006 \\
\hline 12 & Saluran L48 & 0,2 & 0,040 & 0,008 \\
\hline 13 & Saluran L49 & 0,2 & 0,045 & 0,009 \\
\hline 14 & Saluran L50 & 0,2 & 0,045 & 0,009 \\
\hline 15 & Saluran L51 & 0,2 & 0,049 & 0,010 \\
\hline 16 & Saluran L52 & 0,2 & 0,025 & 0,005 \\
\hline 17 & Saluran L53 & 0,2 & 0,040 & 0,008 \\
\hline 18 & Saluran L54 & 0,2 & 0,040 & 0,008 \\
\hline 19 & Saluran L55 & 0,2 & 0,025 & 0,005 \\
\hline 20 & Saluran L56 & 0,2 & 0,035 & 0,007 \\
\hline 21 & Saluran L57 & 0,2 & 0,030 & 0,006 \\
\hline
\end{tabular}




\begin{tabular}{l|l|l|l|l}
22 & Saluran L58 & 0,2 & 0,036 & 0,007 \\
\hline 23 & Saluran L59 & 0,2 & 0,035 & 0,007 \\
\hline 24 & Saluran L60 & 0,2 & 0,052 & 0,010 \\
\hline 25 & Saluran L61 & 0,2 & 0,040 & 0,008 \\
\hline 26 & Saluran L62 & 0,2 & 0,040 & 0,008 \\
\hline 27 & Saluran L63 & 0,2 & 0,030 & 0,006 \\
\hline 28 & Saluran L64 & 0,2 & 0,030 & 0,006 \\
\hline 29 & Saluran L65 & 0,2 & 0,056 & 0,011 \\
\hline 30 & Saluran L66 & 0,2 & 0,080 & 0,016 \\
\hline 31 & Saluran L67 & 0,2 & 0,080 & 0,016 \\
\hline 32 & Saluran L68 & 0,2 & 0,080 & 0,016 \\
\hline 33 & Saluran L69 & 0,2 & 0,064 & 0,013 \\
\hline 34 & Saluran L70 & 0,2 & 0,070 & 0,014 \\
\hline 35 & Saluran L71 & 0,2 & 0,066 & 0,013 \\
\hline
\end{tabular}

Tabel 7.3. Jumlah Frekuensi Kegagalan Section IV

\begin{tabular}{c|c|c}
\hline \multirow{2}{*}{ No } & Nama Peralatan & $\boldsymbol{\lambda}$ \\
& (kegagalan/tahun) \\
\hline 1 & Frekuensi Kegagalan Tabel 6.1 Sec IV & 0,083 \\
\hline 2 & Frekuensi Kegagalan Tabel 6.2 Sec IV & 0,308 \\
\hline \multicolumn{2}{c}{ TOTAL } & $\mathbf{0 , 3 9 1}$ \\
\hline
\end{tabular}

Sedangkan untuk menghitung durasi gangguan (U) setiap titik beban didapat dari penjumlahan hasil perkalian jumlah trafo distribusi yang terganggu danperlu mengalami perbaikan dengan waktu pemadamannya dan dengan hasil perkalian jumlah trafo distribusi yang terganggu. Waktu pemadaman (repair time) pada setiap peralatan ditunjukkan padaTabel 8 .

Tabel 8.1 Tabel Durasi Gangguan Section I

\begin{tabular}{c|l|c|c|c}
\hline No & Nama Peralatan & $\boldsymbol{\lambda}$ & $\begin{array}{c}\text { Waktu } \\
\text { Pemulihan } \\
\text { (jam) }\end{array}$ & $\begin{array}{c}\text { Switching Time } \\
\text { (jam) }\end{array}$ \\
\hline 1 & Circuit Breaker & 0,004 & 10 & 0,15 \\
\hline 2 & Trafo T1-T2 & 0,010 & 10 & 0,15 \\
\hline 3 & Sectionalizer S1 & 0,003 & 10 & 0,15 \\
\hline 4 & Saluran L1 & 0,016 & 3 & 0,15 \\
\hline 5 & Saluran L2 & 0,080 & 3 & 0,15 \\
\hline 6 & Saluran L3 & 0,180 & 3 & 0,15 \\
\hline 7 & Saluran L4 & 0,055 & 3 & 0,15 \\
\hline 8 & Saluran L5 & 0,023 & 3 & 0,15 \\
\hline 9 & Saluran L6 & 0,080 & 3 & 0,15 \\
\hline 10 & Saluran L7 & 0,010 & 3 & 0,15 \\
\hline
\end{tabular}


Tabel 8.2 Tabel Durasi Gangguan Section II

\begin{tabular}{c|l|c|c|c}
\hline No & Nama Peralatan & $\begin{array}{c}\lambda \\
\text { ( kegagalan/tahun) }\end{array}$ & $\begin{array}{c}\text { Waktu Pemulihan } \\
(\mathbf{j a m})\end{array}$ & $\begin{array}{c}\text { Switching Time } \\
(\mathbf{j a m})\end{array}$ \\
\hline 1 & Circuit Breaker & 0,000 & 10 & 0,15 \\
\hline 2 & Trafo T3-T5 & 0,010 & 10 & 0,15 \\
\hline 3 & Sectionalizer S2 & 0,003 & 10 & 0,15 \\
\hline 4 & Saluran L8 & 0,015 & 3 & 0,15 \\
\hline 5 & Saluran L9 & 0,055 & 3 & 0,15 \\
\hline 6 & Saluran L10 & 0,057 & 3 & 0,15 \\
\hline 7 & Saluran L11 & 0,011 & 3 & 0,15 \\
\hline
\end{tabular}

Tabel 8.3 Tabel Durasi Gangguan Section III

\begin{tabular}{|c|c|c|c|c|}
\hline No & Nama Peralatan & $\begin{array}{c}\lambda \\
\text { ( kegagalan/tahun) }\end{array}$ & $\begin{array}{c}\text { Waktu Pemulihan } \\
\text { (jam) }\end{array}$ & $\begin{array}{c}\text { Switching } \\
\text { Time } \\
\text { (jam) }\end{array}$ \\
\hline 1 & Circuit Breaker & 0,000 & 10 & 0,15 \\
\hline 2 & Trafo T3-T6 & 0,155 & 10 & 0,15 \\
\hline 3 & Sectionalizer S3 & 0,003 & 10 & 0,15 \\
\hline 4 & Saluran L12 & 0,010 & 3 & 0,15 \\
\hline 5 & Saluran L13 & 0,010 & 3 & 0,15 \\
\hline 6 & Saluran L14 & 0,010 & 3 & 0,15 \\
\hline 7 & Saluran L15 & 0,078 & 3 & 0,15 \\
\hline 8 & Saluran L16 & 0,086 & 3 & 0,15 \\
\hline 9 & Saluran L17 & 0,085 & 3 & 0,15 \\
\hline 10 & Saluran L18 & 0,186 & 3 & 0,15 \\
\hline 11 & Saluran L19 & 0,190 & 3 & 0,15 \\
\hline 12 & Saluran L20 & 0,110 & 3 & 0,15 \\
\hline 13 & Saluran L21 & 0,090 & 3 & 0,15 \\
\hline 14 & Saluran L22 & 0,030 & 3 & 0,15 \\
\hline 15 & Saluran L23 & 0,040 & 3 & 0,15 \\
\hline 16 & Saluran L24 & 0,030 & 3 & 0,15 \\
\hline 17 & Saluran L25 & 0,040 & 3 & 0,15 \\
\hline 18 & Saluran L26 & 0,005 & 3 & 0,15 \\
\hline 19 & Saluran L27 & 0,040 & 3 & 0,15 \\
\hline 20 & Saluran L28 & 0,015 & 3 & 0,15 \\
\hline 21 & Saluran L29 & 0,130 & 3 & 0,15 \\
\hline 22 & Saluran L30 & 0,055 & 3 & 0,15 \\
\hline 23 & Saluran L31 & 0,064 & 3 & 0,15 \\
\hline 24 & Saluran L32 & 0,060 & 3 & 0,15 \\
\hline 25 & Saluran L33 & 0,040 & 3 & 0,15 \\
\hline 26 & Saluran L34 & 0,076 & 3 & 0,15 \\
\hline 27 & Saluran L35 & 0,200 & 3 & 0,15 \\
\hline 28 & Saluran L36 & 0,008 & 3 & 0,15 \\
\hline
\end{tabular}

Tabel 8.4 Tabel Durasi Gangguan Section IV

\begin{tabular}{c|l|c|c|c}
\hline No & Nama Peralatan & $\boldsymbol{\lambda}$ & $\begin{array}{c}\text { Waktu } \\
\text { Pemulihan } \\
\text { (jam) }\end{array}$ & $\begin{array}{c}\text { Switching } \\
\text { Time } \\
\text { (jam) }\end{array}$ \\
\hline 1 & Circuit Breaker & 0,000 & 10 & 0,15 \\
\hline 2 & Trafo T37-T52 & 0,080 & 10 & 0,15 \\
\hline
\end{tabular}




\begin{tabular}{|c|c|c|c|c|}
\hline 3 & Sectionalizer S & 0,003 & 10 & 0,15 \\
\hline 4 & Saluran L37 & 0,012 & 3 & 0,15 \\
\hline 5 & Saluran L38 & 0,005 & 3 & 0,15 \\
\hline 6 & Saluran L39 & 0,012 & 3 & 0,15 \\
\hline 7 & Saluran L40 & 0,005 & 3 & 0,15 \\
\hline 8 & Saluran L41 & 0,008 & 3 & 0,15 \\
\hline 9 & Saluran L42 & 0,012 & 3 & 0,15 \\
\hline 10 & Saluran L43 & 0,008 & 3 & 0,15 \\
\hline 11 & Saluran L44 & 0,005 & 3 & 0,15 \\
\hline 12 & Saluran L45 & 0,007 & 3 & 0,15 \\
\hline 13 & Saluran L46 & 0,005 & 3 & 0,15 \\
\hline 14 & Saluran L47 & 0,007 & 3 & 0,15 \\
\hline 15 & Saluran L48 & 0,006 & 3 & 0,15 \\
\hline 16 & Saluran L49 & 0,006 & 3 & 0,15 \\
\hline 17 & Saluran L50 & 0,008 & 3 & 0,15 \\
\hline 18 & Saluran L51 & 0,009 & 3 & 0,15 \\
\hline 19 & Saluran L52 & 0,009 & 3 & 0,15 \\
\hline 20 & Saluran L53 & 0,010 & 3 & 0,15 \\
\hline 21 & Saluran L54 & 0,005 & 3 & 0,15 \\
\hline 22 & Saluran L55 & 0,008 & 3 & 0,15 \\
\hline 23 & Saluran L56 & 0,008 & 3 & 0,15 \\
\hline 24 & Saluran L57 & 0,005 & 3 & 0,15 \\
\hline 25 & Saluran L58 & 0,007 & 3 & 0,15 \\
\hline 26 & Saluran L59 & 0,006 & 3 & 0,15 \\
\hline 27 & Saluran L60 & 0,007 & 3 & 0,15 \\
\hline 28 & Saluran L61 & 0,007 & 3 & 0,15 \\
\hline 29 & Saluran L62 & 0,010 & 3 & 0,15 \\
\hline 30 & Saluran L63 & 0,008 & 3 & 0,15 \\
\hline 31 & Saluran L64 & 0,008 & 3 & 0,15 \\
\hline 32 & Saluran L65 & 0,006 & 3 & 0,15 \\
\hline 33 & Saluran L66 & 0,006 & 3 & 0,15 \\
\hline 34 & Saluran L67 & 0,011 & 3 & 0,15 \\
\hline 35 & Saluran L68 & 0,016 & 3 & 0,15 \\
\hline 36 & Saluran L69 & 0,016 & 3 & 0,15 \\
\hline 37 & Saluran L70 & 0,016 & 3 & 0,15 \\
\hline 38 & Saluran L71 & 0,013 & 3 & 0,15 \\
\hline
\end{tabular}

Untuk menghitung durasi gangguan tahunan rata-rata untuk titik bebanU $U_{T B}$ adalah seperti persamaan berikut :

$$
\begin{aligned}
\mathrm{U}_{T B}=\sum_{i=k} \mathrm{U}_{i} & =\text { waktu perbaikan } x \text { Jumlah titikbeban } \\
& =10 \times 2=20
\end{aligned}
$$

Data waktu pemulihan (repair time) section I ditunjukkan pada Tabel 9. 
Tabel 9.1 Tabel Waktu Perbaikan Section I

\begin{tabular}{c|l|c|c|c}
\hline No & Nama Peralatan & $\begin{array}{c}\text { Waktu Perbaikan } \\
(\mathbf{j a m})\end{array}$ & $\begin{array}{c}\text { Jumlah Titik } \\
\text { (titik) }\end{array}$ & $\begin{array}{c}\text { Total Waktu } \\
(\mathbf{j a m})\end{array}$ \\
\hline 1 & Circuit Breaker & 10 & 52 & 520 \\
\hline 2 & Trafo T1-T2 & 10 & 2 & 0,15 \\
\hline 3 & Sectionalizer S1 & 10 & 52 & 520 \\
\hline 4 & Saluran L1 & 3 & 52 & 156 \\
\hline 5 & Saluran L2 & 3 & 52 & 156 \\
\hline 6 & Saluran L3 & 3 & 52 & 156 \\
\hline 7 & Saluran L4 & 3 & 52 & 156 \\
\hline 8 & Saluran L5 & 3 & 52 & 156 \\
\hline 9 & Saluran L6 & 3 & 52 & 156 \\
\hline 10 & Saluran L7 & 3 & 52 & 156 \\
\hline
\end{tabular}

Tabel 9.2 Tabel Waktu Perbaikan Section II

\begin{tabular}{c|l|c|c|c}
\hline No & Nama Peralatan & $\begin{array}{c}\text { Waktu } \\
\text { Perbaikan } \\
\text { (jam) }\end{array}$ & $\begin{array}{c}\text { Jumlah Titik } \\
(\text { titik })\end{array}$ & $\begin{array}{c}\text { Total Waktu } \\
(\mathbf{j a m})\end{array}$ \\
\hline 1 & Circuit Breaker & 10 & 0 & 0 \\
\hline 2 & Trafo T3-T5 & 10 & 3 & 30 \\
\hline 3 & Sectionalizer S2 & 10 & 52 & 520 \\
\hline 4 & Saluran L8 & 3 & 52 & 156 \\
\hline 5 & Saluran L9 & 3 & 52 & 156 \\
\hline 6 & Saluran L10 & 3 & 52 & 156 \\
\hline 7 & Saluran L11 & 3 & 52 & 156 \\
\hline
\end{tabular}

Tabel 9.3 Tabel Waktu Perbaikan Section III

\begin{tabular}{c|l|c|c|c}
\hline No & Nama Peralatan & $\begin{array}{c}\text { Waktu Perbaikan } \\
\text { (jam) }\end{array}$ & $\begin{array}{c}\text { Jumlah Titik } \\
\text { (titik) }\end{array}$ & $\begin{array}{c}\text { Total Waktu } \\
\text { (jam) }\end{array}$ \\
\hline 1 & Circuit Breaker & 10 & 0 & 0 \\
\hline 2 & Trafo T3-T6 & 10 & 31 & 310 \\
\hline 3 & Sectionalizer S3 & 10 & 52 & 520 \\
\hline 4 & Saluran L12 & 3 & 52 & 156 \\
\hline 5 & Saluran L13 & 3 & 52 & 156 \\
\hline 6 & Saluran L14 & 3 & 52 & 156 \\
\hline 7 & Saluran L15 & 3 & 52 & 156 \\
\hline 8 & Saluran L16 & 3 & 52 & 156 \\
\hline 9 & Saluran L17 & 3 & 52 & 156 \\
\hline 10 & Saluran L18 & 3 & 52 & 156 \\
\hline 11 & Saluran L19 & 3 & 52 & 156 \\
\hline 12 & Saluran L20 & 3 & 52 & 156 \\
\hline 13 & Saluran L21 & 3 & 52 & 156 \\
\hline 14 & Saluran L22 & 3 & 52 & 156 \\
\hline 15 & Saluran L23 & 3 & 52 & 156 \\
\hline 16 & Saluran L24 & 3 & 52 & 156 \\
\hline 17 & Saluran L25 & 3 & 52 & 156 \\
\hline 18 & Saluran L26 & 3 & 52 & 156 \\
\hline 19 & Saluran L27 & 3 & 52 & 156 \\
\hline 20 & Saluran L28 & 3 & 52 & 156 \\
\hline 21 & Saluran L29 & 3 & 52 & 156 \\
\hline 22 & Saluran L30 & 3 & 52 & 156 \\
\hline 23 & Saluran L31 & 3 & 52 & 156 \\
\hline 24 & Saluran L32 & 3 & 52 & 156 \\
\hline 25 & Saluran L33 & 3 & 52 & 156 \\
\hline
\end{tabular}




\begin{tabular}{l|l|l|l|l}
26 & Saluran L34 & 3 & 52 & 156 \\
\hline 27 & Saluran L35 & 3 & 52 & 156 \\
\hline 28 & Saluran L36 & 3 & 52 & 156 \\
\hline
\end{tabular}

Tabel 9.4 Tabel Waktu Perbaikan Section IV

\begin{tabular}{|c|c|c|c|c|}
\hline No & Nama Peralatan & $\begin{array}{c}\text { Waktu Perbaikan } \\
\text { (jam) }\end{array}$ & $\begin{array}{c}\text { Jumlah Titik } \\
\text { (titik) }\end{array}$ & $\begin{array}{c}\text { Total Waktu } \\
\text { (jam) }\end{array}$ \\
\hline 1 & Circuit Breaker & 10 & 52 & 520 \\
\hline 2 & Trafo T37-T52 & 10 & 16 & 160 \\
\hline 3 & Sectionalizer S & 10 & 52 & 520 \\
\hline 4 & Saluran L37 & 3 & 52 & 156 \\
\hline 5 & Saluran L38 & 3 & 52 & 156 \\
\hline 6 & Saluran L39 & 3 & 52 & 156 \\
\hline 7 & Saluran L40 & 3 & 52 & 156 \\
\hline 8 & Saluran L41 & 3 & 52 & 156 \\
\hline 9 & Saluran L42 & 3 & 52 & 156 \\
\hline 10 & Saluran L43 & 3 & 52 & 156 \\
\hline 11 & Saluran L44 & 3 & 52 & 156 \\
\hline 12 & Saluran L45 & 3 & 52 & 156 \\
\hline 13 & Saluran L46 & 3 & 52 & 156 \\
\hline 14 & Saluran L47 & 3 & 52 & 156 \\
\hline 15 & Saluran L48 & 3 & 52 & 156 \\
\hline 16 & Saluran L49 & 3 & 52 & 156 \\
\hline 17 & Saluran L50 & 3 & 52 & 156 \\
\hline 18 & Saluran L51 & 3 & 52 & 156 \\
\hline 19 & Saluran L52 & 3 & 52 & 156 \\
\hline 20 & Saluran L53 & 3 & 52 & 156 \\
\hline 21 & Saluran L54 & 3 & 52 & 156 \\
\hline 22 & Saluran L55 & 3 & 52 & 156 \\
\hline 23 & Saluran L56 & 3 & 52 & 156 \\
\hline 24 & Saluran L57 & 3 & 52 & 156 \\
\hline 25 & Saluran L58 & 3 & 52 & 156 \\
\hline 26 & Saluran L59 & 3 & 52 & 156 \\
\hline 27 & Saluran L60 & 3 & 52 & 156 \\
\hline 28 & Saluran L61 & 3 & 52 & 156 \\
\hline 29 & Saluran L62 & 3 & 52 & 156 \\
\hline 30 & Saluran L63 & 3 & 52 & 156 \\
\hline 31 & Saluran L64 & 3 & 52 & 156 \\
\hline 32 & Saluran L65 & 3 & 52 & 156 \\
\hline 33 & Saluran L66 & 3 & 52 & 156 \\
\hline 34 & Saluran L67 & 3 & 52 & 156 \\
\hline 35 & Saluran L68 & 3 & 52 & 156 \\
\hline 36 & Saluran L69 & 3 & 52 & 156 \\
\hline 37 & Saluran L70 & 3 & 52 & 156 \\
\hline 38 & Saluran L71 & 3 & 52 & 156 \\
\hline
\end{tabular}

Sesuai dengan persamaan (3) didapatkan nilai SAIFI titik beban dengan cara mengalikan jumlah konsumen pada tiap-tiap titik beban dengan frekuensi kegagalan $(\lambda)$ titik beban 
kemudian membaginya dengan total jumlah konsumen yang ada pada system Penyulang Pajajaran. Perhitungan nilai SAIFI dapat dilihat di persamaan dibawah ini:

$$
\text { SAIFI T1 }=\frac{\sum \mathrm{NTB} \times \lambda_{T B}}{N}=\frac{360 \times 0,01}{9.914}=0,000533 \mathrm{kali} / \mathrm{tahun}
$$

Sesuai dengan persamaan (4) didapatkan nilai SAIDI titik beban dengan cara mengalikan jumlah konsumen pada tiap-tiap titik beban dengan durasi kegagalan (U) titik beban, kemudian membaginya dengan total jumlah konsumen yang ada pada system PenyulangPajajaran.

Perhitungannilai SAIDI dapatdilihat di persamaandibawahini:

$$
\text { SAIDI T1 }=\frac{\sum \lambda_{T B} \mathrm{X} \mathrm{U}_{T B}}{N}=\frac{0,01 \times 20}{9.914}=0,000029 \mathrm{jam} / \text { tahun }
$$

Hasil perhitungan SAIFI dan SAIDI pada section 1-4ditunjukkan padaTabel 10.1

Tabel 10.1 Hasil SAIFI dan SAIDI Section I

\begin{tabular}{c|l|c|c}
\hline \multirow{2}{*}{ No } & \multirow{2}{*}{ Nama Peralatan } & \multicolumn{2}{|c}{ Indeks Keandalan Section } \\
\cline { 3 - 4 } & & SAIFI & SAIDI \\
\hline 1 & Circuit Breaker & 0,00400 & 0,00031 \\
\hline 2 & Trafo T1-T2 & 0,00053 & 0,00003 \\
\hline 3 & Sectionalizer S1 & 0,00300 & 0,00023 \\
\hline 4 & Saluran L1 & 0,01600 & 0,01600 \\
\hline 5 & Saluran L2 & 0,08000 & 0,08000 \\
\hline 6 & Saluran L3 & 0,18000 & 0,18000 \\
\hline 7 & Saluran L4 & 0,05500 & 0,05500 \\
\hline 8 & Saluran L5 & 0,02300 & 0,02300 \\
\hline 9 & Saluran L6 & 0,08000 & 0,08000 \\
\hline 10 & Saluran L7 & 0,01000 & 0,01000 \\
\hline & TOTAL & $\mathbf{0 , 4 5 1 5 3}$ & $\mathbf{0 , 4 4 4 5 6}$ \\
\hline
\end{tabular}

Tabel 10.2 Hasil SAIFI dan SAIDI Section II

\begin{tabular}{c|l|c|c}
\hline \multirow{2}{*}{ No } & \multirow{2}{*}{ Nama Peralatan } & \multicolumn{2}{|c}{ Indeks Keandalan Section } \\
\cline { 3 - 4 } & & SAIFI & SAIDI \\
\hline 1 & Circuit Breaker & 0,00000 & 0,00000 \\
\hline 2 & Trafo T3-T5 & 0,00089 & 0,00007 \\
\hline 3 & Sectionalizer S2 & 0,00300 & 0,00023 \\
\hline 4 & Saluran L8 & 0,01500 & 0,01500 \\
\hline 5 & Saluran L9 & 0,05500 & 0,05500 \\
\hline 6 & Saluran L10 & 0,05700 & 0,05700 \\
\hline 7 & Saluran L11 & 0,01100 & 0,01100 \\
\hline & TOTAL & $\mathbf{0 , 1 4 1 8 9}$ & $\mathbf{0 , 1 3 8 3 0}$ \\
\hline
\end{tabular}


Tabel 10.3 Hasil SAIFI dan SAIDI Section III

\begin{tabular}{|c|c|c|c|}
\hline \multirow{2}{*}{ No } & \multirow{2}{*}{ Nama Peralatan } & \multicolumn{2}{|c|}{ Indeks Keandalan Section } \\
\hline & & SAIFI & SAIDI \\
\hline 1 & Circuit Breaker & 0,00000 & 0,00000 \\
\hline 2 & Trafo T6-T36 & 0,09168 & 0,00705 \\
\hline 3 & Sectionalizer S3 & 0,00300 & 0,00023 \\
\hline 4 & Saluran L12 & 0,01000 & 0,01000 \\
\hline 5 & Saluran L13 & 0,01000 & 0,01000 \\
\hline 6 & Saluran L14 & 0,01000 & 0,01000 \\
\hline 7 & Saluran L15 & 0,07800 & 0,07800 \\
\hline 8 & Saluran L16 & 0,08620 & 0,08620 \\
\hline 9 & Saluran L17 & 0,08500 & 0,08500 \\
\hline 10 & Saluran L18 & 0,18600 & 0,18600 \\
\hline 11 & Saluran L19 & 0,19000 & 0,19000 \\
\hline 12 & Saluran L20 & 0,11000 & 0,11000 \\
\hline 13 & Saluran L21 & 0,09000 & 0,09000 \\
\hline 14 & Saluran L22 & 0,03000 & 0,03000 \\
\hline 15 & Saluran L23 & 0,02300 & 0,02300 \\
\hline 16 & Saluran L24 & 0,03000 & 0,03000 \\
\hline 17 & Saluran L25 & 0,04000 & 0,04000 \\
\hline 18 & Saluran L26 & 0,00500 & 0,00500 \\
\hline 19 & Saluran L27 & 0,04000 & 0,04000 \\
\hline 20 & Saluran L28 & 0,01500 & 0,01500 \\
\hline 21 & Saluran L29 & 0,13000 & 0,13000 \\
\hline 22 & Saluran L30 & 0,05500 & 0,05500 \\
\hline 23 & Saluran L31 & 0,06380 & 0,06380 \\
\hline 24 & Saluran L32 & 0,06000 & 0,06000 \\
\hline 25 & Saluran L33 & 0,04000 & 0,04000 \\
\hline 26 & Saluran L34 & 0,07600 & 0,07600 \\
\hline 27 & Saluran L35 & 0,20000 & 0,20000 \\
\hline 28 & Saluran L36 & 0,00800 & 0,00800 \\
\hline & TOTAL & 1,76568 & 1,67827 \\
\hline
\end{tabular}

Tabel 10.4 Hasil SAIFI dan SAIDI Section IV

\begin{tabular}{|c|l|c|c|}
\hline \multirow{2}{*}{ No } & \multirow{2}{*}{ Nama Peralatan } & \multicolumn{2}{|c|}{ Indeks Keandalan Section } \\
\cline { 3 - 4 } & & SAIFI & SAIDI \\
\hline 1 & Circuit Breaker & 0,00000 & 0,00000 \\
\hline 2 & Trafo T37-T52 & 0,02368 & 0,00188 \\
\hline 3 & Sectionalizer S4 & 0,00300 & 0,00023 \\
\hline 4 & Saluran L37 & 0,01200 & 0,01200 \\
\hline 5 & Saluran L38 & 0,00500 & 0,00500 \\
\hline 6 & Saluran L39 & 0,00800 & 0,00800 \\
\hline 7 & Saluran L40 & 0,01200 & 0,01200 \\
\hline 8 & Saluran L41 & 0,00800 & 0,00800 \\
\hline 9 & Saluran L42 & 0,00500 & 0,00500 \\
\hline 10 & Saluran L43 & 0,00700 & 0,00700 \\
\hline 11 & Saluran L44 & 0,00500 & 0,00500 \\
\hline 12 & Saluran L45 & 0,00700 & 0,00700 \\
\hline 13 & Saluran L46 & 0,00600 & 0,00600 \\
\hline
\end{tabular}




\begin{tabular}{|c|c|c|c|}
\hline 14 & Saluran L47 & 0,00600 & 0,00600 \\
\hline 15 & Saluran L48 & 0,00800 & 0,00800 \\
\hline 16 & Saluran L49 & 0,00900 & 0,00900 \\
\hline 17 & Saluran L50 & 0,00900 & 0,00900 \\
\hline 18 & Saluran L51 & 0,00970 & 0,00970 \\
\hline 19 & Saluran L52 & 0,00500 & 0,00500 \\
\hline 20 & Saluran L53 & 0,00800 & 0,00800 \\
\hline 21 & Saluran L54 & 0,00800 & 0,00800 \\
\hline 22 & Saluran L55 & 0,00500 & 0,00500 \\
\hline 23 & Saluran L56 & 0,00700 & 0,00700 \\
\hline 24 & Saluran L57 & 0,00600 & 0,00600 \\
\hline 25 & Saluran L58 & 0,00720 & 0,00720 \\
\hline 26 & Saluran L59 & 0,00700 & 0,00700 \\
\hline 27 & Saluran L60 & 0,01040 & 0,01040 \\
\hline 28 & Saluran L61 & 0,00800 & 0,00800 \\
\hline 29 & Saluran L62 & 0,00800 & 0,00800 \\
\hline 30 & Saluran L63 & 0,00600 & 0,00600 \\
\hline 31 & Saluran L64 & 0,00600 & 0,00600 \\
\hline 32 & Saluran L65 & 0,01120 & 0,01120 \\
\hline 33 & Saluran L66 & 0,01600 & 0,01600 \\
\hline 34 & Saluran L67 & 0,01600 & 0,01600 \\
\hline 35 & Saluran L68 & 0,01600 & 0,01600 \\
\hline 36 & Saluran L69 & 0,01280 & 0,01280 \\
\hline 37 & Saluran L70 & 0,01400 & 0,01400 \\
\hline 38 & Saluran L71 & 0,01320 & 0,01320 \\
\hline \multicolumn{2}{|r|}{ TOTAL } & 0,33418 & 0,30961 \\
\hline
\end{tabular}

Dengan langkah analisis yang sama dan perhitungan yang sama pada setiap peralatan distribusi Penyulang Pajajaran dari Section I hingga Section IV, maka nilai SAIFI dan SAIDI setiap section ditunjukkan pada Tabel 11.

Tabel 11. Tabel Hasil Perhitungan SAIDI dan SAIFI seluruh Section

\begin{tabular}{|c|l|c|c|}
\hline \multirow{2}{*}{ No } & \multirow{2}{*}{ Nama Section } & \multicolumn{2}{|c|}{ Indeks Keandalan Section } \\
\cline { 3 - 4 } & & SAIFI & SAIDI \\
\hline 1 & Section I & 0,45153 & 0,44456 \\
\hline 2 & Section II & 0,14189 & 0,13829 \\
\hline 3 & Section III & 1,76581 & 1,67827 \\
\hline 4 & Section IV & 0,33418 & 0,30961 \\
\hline \multicolumn{2}{r|}{ TOTAL } & $\mathbf{2 , 6 9 3 4 0}$ & $\mathbf{2 , 5 7 0 7 4}$ \\
\hline
\end{tabular}

\section{Realisasi SAIDI - SAIFI Penyulang Pajajaran}

Realisasi SAIDI SAIFI Penyulang Pajajaran diambil dari data laporan kinerja penyulang mulai dari bulan Juni 2017 sampai dengan bulan Mei 2018 sebagai berikut : 
Tabel 12. Realisasi SAIFI

\begin{tabular}{c|l|c|c|c|c|c}
\hline No & \multicolumn{1}{|c|}{ Bulan } & $\begin{array}{c}\text { Jumlah } \\
\text { Gangguan }\end{array}$ & Target & $\begin{array}{c}\text { Jumlah } \\
\text { Pelanggan }\end{array}$ & $\begin{array}{c}\text { Pelanggan } \\
\text { Unit }\end{array}$ & SAIFI \\
\hline 1 & Juni 2017 & 5 & 1 & 9.760 & 125,031 & 0,3903 \\
\hline 2 & Juli 2017 & 4 & 2 & 9.780 & 125,848 & 0,3109 \\
\hline 3 & Agustus 2017 & 3 & 2 & 9.796 & 126,876 & 0,2316 \\
\hline 4 & September 2017 & 9 & 3 & 9.824 & 127,602 & 0,6929 \\
\hline 5 & Oktober 2017 & 3 & 2 & 9.856 & 128,319 & 0,2304 \\
\hline 6 & November 2017 & 5 & 2 & 9.874 & 129,003 & 0,3827 \\
\hline 7 & Desember 2017 & 6 & 2 & 9.879 & 129,622 & 0,4573 \\
\hline 8 & Januari 2018 & 6 & 1 & 9.883 & 130,312 & 0,4550 \\
\hline 9 & Februari 2018 & 5 & 4 & 9.890 & 130,857 & 0,3779 \\
\hline 10 & Maret 2018 & 12 & 1 & 9.898 & 131,452 & 0,9036 \\
\hline 11 & April 2018 & 3 & 1 & 9.904 & 132,125 & 0,2249 \\
\hline 12 & Mei 2018 & 0 & 2 & 9.914 & 132,582 & - \\
\hline & \multicolumn{1}{|c|}{ Total } & 61 & 23 & & & 4,6575 \\
\hline
\end{tabular}

Realisasi SAIFI Periode juni 2017 - Mei 2018 Penyulang Pajajaran adalah sebesar 4,6575 Kali/Pelanggan.

Tabel 13. Realisasi Saidi

\begin{tabular}{c|l|c|c|c|c|c}
\hline No & \multicolumn{1}{|c|}{ Bulan } & $\begin{array}{c}\text { Durasi } \\
\text { Padam } \\
\text { (jam) }\end{array}$ & Target & $\begin{array}{c}\text { Jumlah } \\
\text { Pelanggan }\end{array}$ & $\begin{array}{c}\text { Pelanggan } \\
\text { Unit }\end{array}$ & SAIFI \\
\hline 1 & Juni 2017 & 1,65 & 1,57 & 9.760 & 125,031 & 0,1288 \\
\hline 2 & Juli 2017 & 4,52 & 1,75 & 9.780 & 125,848 & 0,3513 \\
\hline 3 & Agustus 2017 & 16,90 & 1,28 & 9.796 & 126,876 & 1,3048 \\
\hline 4 & September 2017 & 8,60 & 4,02 & 9.824 & 127,602 & 0,6621 \\
\hline 5 & Oktober 2017 & 3,93 & 3,37 & 9.856 & 128,319 & 0,3019 \\
\hline 6 & November 2017 & 6,62 & 5,42 & 9.874 & 129,003 & 0,5067 \\
\hline 7 & Desember 2017 & 6,23 & 0,80 & 9.879 & 129,622 & 0,4750 \\
\hline 8 & Januari 2018 & 6,23 & 1,07 & 9.883 & 130,312 & 0,4727 \\
\hline 9 & Februari 2018 & 4,48 & 1,77 & 9.890 & 130,857 & 0,3388 \\
\hline 10 & Maret 2018 & 12,75 & 2,56 & 9.898 & 131,452 & 0,9600 \\
\hline 11 & April 2018 & 0,67 & 8,04 & 9.904 & 132,125 & 0,0502 \\
\hline 12 & Mei 2018 & 0,00 & 4,92 & 9.914 & 132,582 & - \\
\hline \multicolumn{1}{|c|}{ Total } & 72,58 & 36,57 & & & $\mathbf{5 , 5 5 2 3}$ \\
\hline
\end{tabular}

Realisasi SAIFI Periode juni 2017 - Mei 2018 Penyulang Pajajaran adalah sebesar 5,5524 Jam/Pelanggan 
a. Grafik Kali Gangguan Penyulang Pajajaran

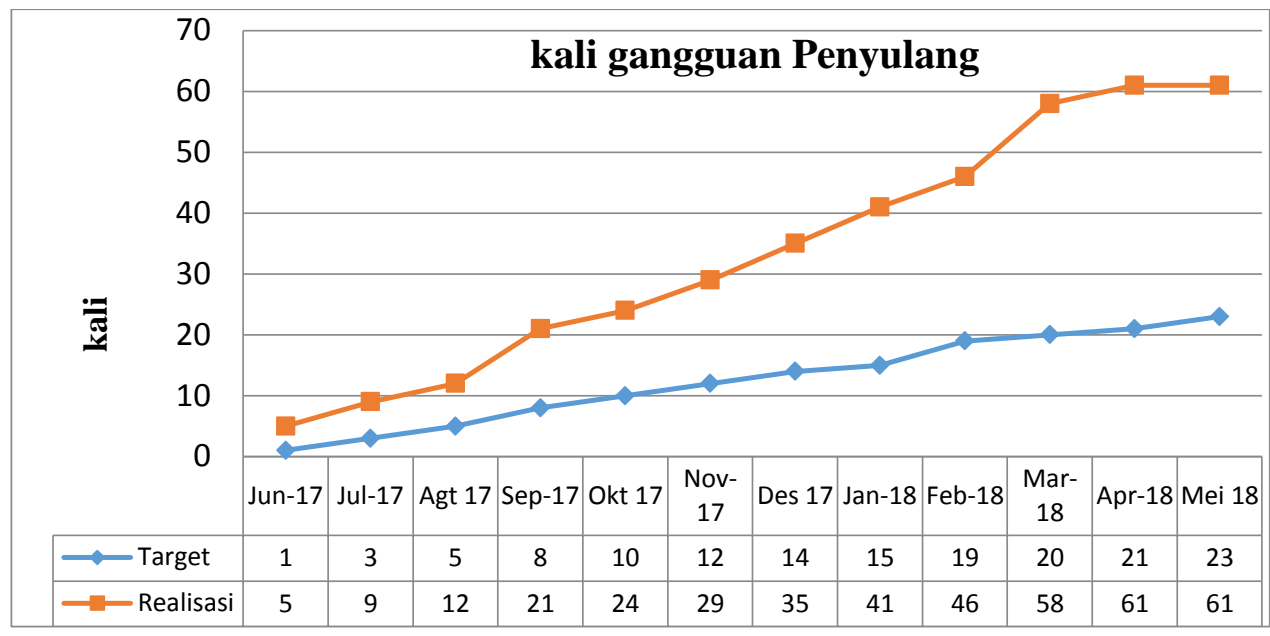

Gambar 2. Kali Gangguan Penyulang Pajajaran

\section{b. Grafik Lama Gangguan Penyulang Pajajaran}

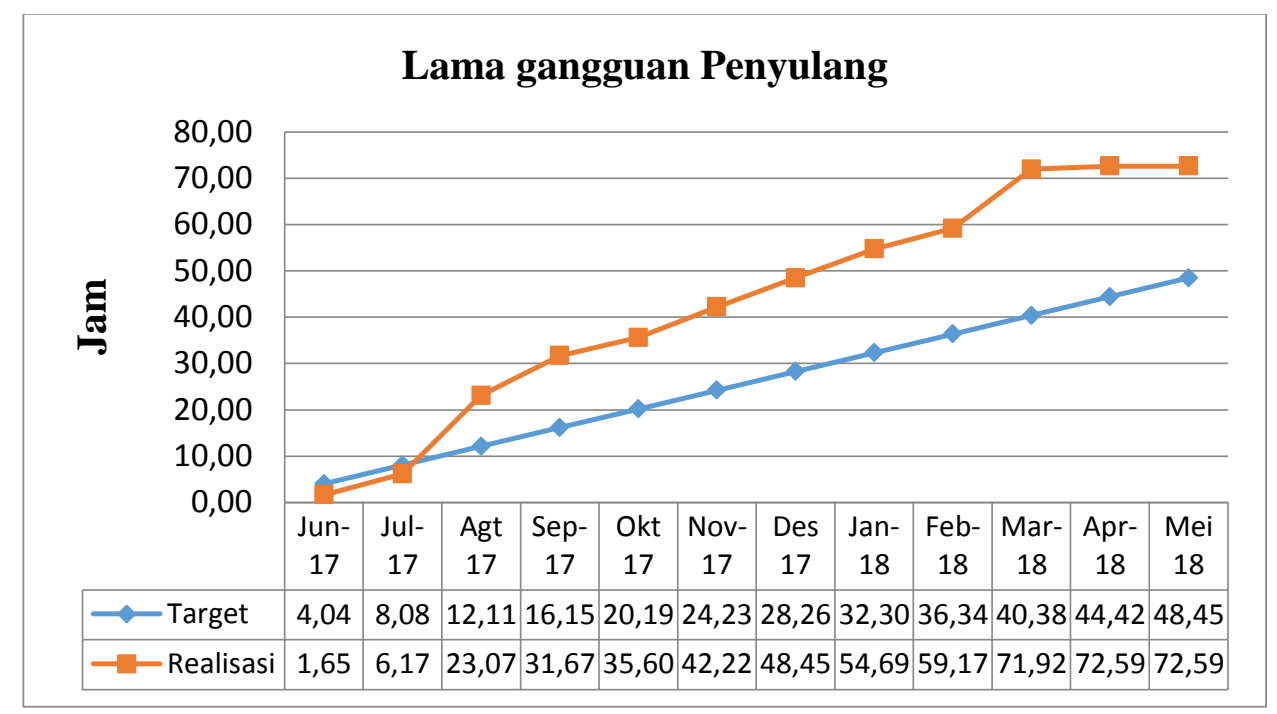

Gambar 3. Lama Gangguan Penyulang Pajajaran

\section{Perbandingan Hasil Perhitungan SAIDI SAIFI}

Berdasarkan hasil Perhitungan dengan Metode Section Technique, hasil laporan kegiatan Penyulang dan dibandingkan dengan target, diperoleh data sebagai berikut :

Tabel 14. Hasil Perbandingan SAIDI SAIFI

\begin{tabular}{l|c|c|c|c|c}
\hline \multirow{2}{*}{ Indeks } & \multirow{2}{*}{$\begin{array}{c}\text { Satuan } \\
\text { (per tahun) }\end{array}$} & $\begin{array}{c}\text { IEEE } \\
\mathbf{2 0 1 7}\end{array}$ & $\begin{array}{c}\text { Target } \\
\text { Rayon }\end{array}$ & $\begin{array}{c}\text { Metode } \\
\text { Section Technique }\end{array}$ & Realiasi \\
\hline SAIDI & Jam/Pelanggan & 4,3833 & 3,3857 & 2,5707 & 5,5524 \\
\hline SAIFI & Jam/Pelanggan & 1,5900 & 2,4901 & 2,6911 & 4,6575 \\
\hline
\end{tabular}




\section{KESIMPULAN}

Kesimpulan dari analisis yang telah dilakukan yaitu :

1. Berdasarkan hasil perhitungan dengan Metode Section Technique, realisasi kegiatan Penyulang didapatkan tingkat keandalan SAIDI SAIFI Penyulang Pajajaran Realisasi terhadap target adalah sebesar :

- $\quad$ SAIFI : $36,01 \%$

- $\quad$ SAIFI : $12,96 \%$

2. Angka Realisasi Saidi Saifi Penyulang Pajajaran PLN Pada Gardu Induk New Jakabaring masih lebih tinggi dibandingkan dengan target, hal ini menunjukkan keandalan Penyulang Pajajaran masih rendah, penyebabnya adalah tingginya gangguan jaringan dan banyaknya pemadaman akibat adanya pekerjaan pemeliharaan dan pembangunan jaringan yang berkaitan dengan Penyulang Pajajaran. Upaya yang dapat dilakukan untuk meningkatkan keandalan antara lain dengan mengintensifkan kegiatan pemeliharaan penyulang, mengatur sesingkat mungkin jadwal pemadaman akibat pekerjaan pemeliharaan.

\section{DAFTAR PUSTAKA}

[1] Wahyudi Ragil, R., \& Umar, S.T. (2016). Analisis Keandalan Sistem Jaringan Distribusi Di Gardu Induk Bringin Penyulang -2 Pt. Pln (Persero) UI salatiga Dengan Metode Section Technique (Doctoral dissertation, Universitas Muhammadiyah Surakarta).

[2] Putra, D.E., \& N. Nurdiana. R. Simatupang Analisa Keandalan Penyulang 20 Kv Di Jakabaring Sport City (Jsc) Dalam Menghadapi Asian Games Ke XVIII Tahun 2018. JURNAL SURYA ENERGI, 2(1) 145 -156

[3] Putra, D.E., \& Siahaan,A.(2017). Studi Penerapan Over Load Shedding(Ols) Relay Pada Sisi Sekunder Transformator Daya 20 MVA Penyulang Aries $20 \mathrm{KV}$ Di Gardu Induk lahat. JURNAL AMPERE, 2(1)

[4] Marsudi, D. (2015), Operasi Sistem Tenaga Listrik jilid. Yogyakarta Graha Ilmu

[5] IEEE Std 1366-1998, The Institute Electrical Electronic Engineering, 1998, USA

[6] IEEE P1366-2017, The Institute Electrical Electronic Engineering, 2017, USA

[7] SPLN No. 68-2 1986 PT. PLN (Persero). 1986 Jakarta

[8] SPLN No. 59: 1985 PT. PLN (Persero).1995 Jakarta

[9] Short,T.A.(2014) Electrical Power Distribution Handbook. CRC Press 